\title{
Factors affecting competition of three strains of rhizobia nodulating groundnut, Arachis hypogaea*
}

\author{
'BY P. T. C. NAMBIAR, V. ANJAIAH AND B. SRINIVASA RAO \\ International Crops Research Institute for the Semi-Arid Tropics \\ (ICRISAT). Patancheru PO. Andhra Pradesh 502 324. India
}

(Accepted 6 Octoher 1986)

\begin{abstract}
SUMMARY
The nitrogen $\left(\mathrm{N}_{2}\right)$ fixing ability of three strains of rhizobia (NC 92, NC 43.3, and TAL 176) was compared in groundnut cv. Robut 33-1. The competitiveness of these strains in pot culture in a sand-vermiculite medium and with native rhizobia in the field was also investigated. In pot culture, NC 43.3 formed more nodules than TAL 176 and NC 92. Nodules formed by NC 43.3 and NC 92 fixed more $\mathrm{N}_{2}$ (as measured by total $\mathrm{N}$ content in the plants at 42 days after sowing) than nodules formed by TAL 176 . TAL 176 was a poor competitor compared with NC 92, NC 43.3, or with native rhizobia in the field. NC 92 when mixed with NC 43.3 ( $10^{6}$ cells seed ${ }^{-1}$ of each strain) formed only $21 \%$ of the nodules, but when independently inoculated in the soil containing native rhizobia, the two-strains formed similar percentages of nodules. Thirty percent of the nodules in two strain combinations of NC 43.3 and NC 92 showed double occupancy. Strain NC 43.3 formed nodules earlier than NC 92 and TAL 176 and this may be one of the factors responsible for its better $\mathrm{N}_{2}$-fixation and competitiveness. Nodules formed earlier by one strain (NC 92 or TAL 176) were found to have no effect on the subsequent nodulation by the other (TAL 176 or NC 92) strain. Although NC 92 and NC 43.3 were equally competitive with native rhizobia in the field and NC 43.3 fixed more $\mathrm{N}_{2}$ than NC 92 in pot culture, earlier experiments indicated that only inoculation with NC 92 increased pod yield in field trials.
\end{abstract}

\section{INTRODUCTION}

In many trials, inoculation with effective strains of rhizobia has not increased groundnut yields (Lopes, 1977; Subba Rao, 1976; van der Merwe, Strijdom \& Uys, 1974). However, recent work at the International Crops Research Institute for the Semi-Arid Tropics (ICRISAT), near Hyderabad in India demonstrated that inoculation with Rhizobium strain NC 92 increased the yields of groundnut cultivar Robut 33-1 in fields with previous histories of nodulated groundnut crops (Nambiar \& Dart, 1980; Nambiar, Dart, Srinivasa Rao \& Ravishankar 1982; Nambiar, Dart, Srinivasa Rao \& Ravishankar, 1984a; Nambiar, 1985). Subsequently it was observed that NC 92 increased yields of this groundnut cultivar at several locations in India (Anon., 1983a). Higher yields also resulted when the following other genotypes were inoculated: ICGS 15, ICGS 27, JL 24 (Anon., 1983b; Nambiar et al., 1984a) ICGS 11, ICGS 12, at ICRISAT Center (Anon., 1985), JL 24 at Junagadh, India (Joshi \& Kulkarni, 1983) and 28-206 in Sanguéré in Cameroon (Anon., 1983c).

Closer study of strain NC 92 may reveal the reasons why it succeeds where other strains fail and thus provide improved selection criteria for developing better inoculants. We have earlier reported that inoculation with NC 92 in a field containing native rhizobia resulted in the formation of $25-40 \%$ NC 92 nodules (Nambiar, Srinivasa Rao \& Anjaiah, 1984b). This 
paper reports the results of experiments that examined the competitiveness and relative $\mathrm{N}_{2}$ fixing ability of strain NC 92 compared with two other strains, NC 43.3 and TAL 176.

\section{MATERIALS AND METHODS}

\section{Strains of rhizobia and groundnut cultivars}

Rhizobium strains NC 92 and NC 43.3 were obtained from Dr G. H. Elkan, North Carolina State University, Raleigh, USA, and strain TAL 176 from NifTAL, Hawaii, USA. The groundnut cultivar used was Robut 33-1, a virginia type.

\section{Enumeration of soil rhizobia and identification of inoculant strain in nodules}

Enumeration of soil rhizobia and identification of nodules formed by the inoculant strains were carried out using enzyme-linked immunosorbent assay (ELISA, Clark \& Adams, 1977) as described previously (Nambiar \& Anjaiah, 1985; Nambiar et al., 1984b).

\section{Green house experiments}

Five pot culture experiments were conducted using a sterilised sand-vermiculite $(2: 1)$ medium in 17-cm diameter pots using previously described methods (Nambiar \& Dart, 1980; Nambiar et al., 1983). The plants were watered with an $\mathrm{N}$-free nutrient solution. Nodules were manually separated from the roots and the nodule number recorded. The nodules were dried at $80^{\circ} \mathrm{C}$ for $24 \mathrm{~h}$ and their dry weights recorded.

The total nitrogen in plant parts was estimated as described by Nambiar et al. (1983), and since no mineral nitrogen was added in the nutrient solution, the total nitrogen in the plant represents that fixed during the growth period.

Expt 1. Differential rhizosphere colonisation/survival. Seeds were inoculated with strains NC 92 and TAL 176 at two population levels, i.e. $1 \times 10^{4}$ and $1 \times 10^{6}$ cells $\mathrm{g}^{-1}$ medium for NC 92 and $5 \times 10^{4}$ and $5 \times 10^{6}$ cells $\mathrm{g}^{-1}$ medium for TAL 176 respectively, as individual strains, and as mixtures of both strains. The treatments were arranged in a randomised block design with four replications (Table 1). Populations of NC 92 and TAL 176 in the rhizosphere were estimated 20 days after sowing (DAS).

Table 1. Survival of strains NC 92 and TAL 176 with rhizosphere population $g^{-1}$ medium of the inoculant strain $(s) 0$ days and 20 days after sowing in pots

\begin{tabular}{|c|c|c|c|c|}
\hline \multirow[b]{3}{*}{ Inoculant } & \multicolumn{4}{|c|}{ Population $\times 10^{4}$ cells $\mathrm{g}^{-1}$ sand-vermiculite medium } \\
\hline & \multicolumn{2}{|c|}{ Strain NC 92} & \multicolumn{2}{|c|}{ Strain TAL 176} \\
\hline & Initial & 20 DAS & Initial & 20 DAS \\
\hline NC $92,10^{4}$ & $1^{*}$ & $9.95(4.997) \dagger$ & - & - \\
\hline TAL $176,10^{4}$ & - & - & 5 & $53.3(5 \cdot 720)$ \\
\hline NC $92,10^{6}$ & 100 & $10.99(5.040)$ & - & - \\
\hline TAL $176,10^{\circ}$ & & & 500 & $66.5(5.822)$ \\
\hline \multicolumn{5}{|c|}{$\begin{array}{l}\text { Mixed strains } \\
\text { NC } 92+\text { TAL } 176\end{array}$} \\
\hline $10^{4}+10^{4}$ & 1 & $9.15(4.961)$ & 5 & $51.4(5.711)$ \\
\hline $10^{4}+10^{6}$ & 1 & $7.46(4.873)$ & 500 & $61 \cdot 7(5 \cdot 788)$ \\
\hline $10^{6}+10^{4}$ & 100 & 9.89 (4.995) & 5 & $50.5(5.703)$ \\
\hline $10^{6}+10^{6}$ & 100 & $10.50(5.019)$ & 500 & $74 \cdot 1(5 \cdot 869)$ \\
\hline S.E. & & $( \pm 0.0156)$ & & $( \pm 0.0238)$ \\
\hline
\end{tabular}


Expt 2. To compare the rates of nodule development for three strains of rhizobia. This experiment was designed to study the time taken by the three strains to form visible nodules on cv. Robut 33-1. The seeds were inoculated with the desired strain $\left(10^{8}\right.$ cells seed $\left.{ }^{-1}\right)$. The treatments were arranged in a randomised block design with three replications, and sample plants were harvested at 2-3 day intervals from 15 DAS to 25 DAS. Nodules per plant were recorded.

Expt 3. To study the effect of nodules formed by one strain on subsequent nodulation by a second strain. The objective of these experiments was to study possible interference between nodulating strains. The seeds were inoculated with a single strain (TAL 176 or NC 92) at $10^{4}$ cells seed ${ }^{-1}$ (see Table 2 for the list of treatments). The plants were carefully removed 20 DAS, their roots washed with sterile water, and transplanted into a sand-vermiculite medium containing the other strain. Thus, plants initially nodulated by TAL 176 were transplanted into a medium containing NC 92, and vice versa. The treatments were arranged in a randomised block design replicated four times. The plants were grown for 40 days after transplanting, and their nodules were then typed by ELISA to identify the causal strains.

Expt 4. To measure the $\mathrm{N}_{2}$-fixing ability of the test strains. Three strains, TAL 176, NC 43.3, and NC 92 were tested for $\mathrm{N}_{2}$-fixing efficiency as described earlier (Nambiar \& Dart, 1980). Treatments (Table 3 ) were arranged in a randomised block design replicated five times. Since higher Rhizobium populations were required for maximum $\mathrm{N}_{2}$-fixation (Nambiar et al., 1983) the inoculum level used in this experiment was $10^{8}$ cells seed ${ }^{-1}$. Plants were harvested 42 DAS.

Expt 5. To determine the relative competitiveness of the test strains in two-strain mixtures. The treatments (listed in Table 4) consisted of: (a) single strains inoculated at $10^{3}$ and $10^{6}$ cells seed $^{-1}(\mathrm{~b})$ mixtures of these strains at $10^{3}$ and at $10^{6}$ cells seed ${ }^{-1}$ in two-strain combinations, so that each mixture contained $10^{3}+10^{3}$, or $10^{6}+10^{6}$, or $10^{3}+10^{6}$, or $10^{6}+10^{3}$ cells seed -1 for each of the two-strain combinations, except for NC 43.3 at $10^{6}$ cells seed $^{-1}$ with NC 92 and TAL 176 at $10^{3}$. The experiment was laid out in a rectangular lattice design with three replications.

\section{Field experiment}

One experiment was conducted in an Alfisol field to study the competitiveness of the test strains with native soil rhizobia during the 1984 rainy season at ICRISAT Center, Patancheru, near Hyderabad. The plots were fertilised with basal single superphosphate $\left(17 \mathrm{~kg} \mathrm{P} \mathrm{ha}^{-1}\right)$; gypsum ( $400 \mathrm{~kg} \mathrm{ha}^{-1}$ ) was applied at flowering. The plots (beds) were $1 \cdot 2 \mathrm{~m}$ wide by $5 \mathrm{~m}$ long and seeds were sown in four rows at $30-\mathrm{cm}$ row spacing with $10 \mathrm{~cm}$ between plants. The crop was sown on 25 June 1984, and sampled on 15 October 1984. Treatments and experimental design were the same as in the greenhouse, Expt 5.

Table 2. Effect of nodules formed by one strain of $\mathrm{R}$ hizobium on subsequent nodulation by another

$\begin{array}{lcccccc}\begin{array}{c}\text { 1st } \\ \text { inoculation }\end{array} & \begin{array}{c}\text { 2nd } \\ \text { inoculation }\end{array} & \begin{array}{c}\text { Nodule } \\ \text { number } \\ \text { plant }\end{array} & \begin{array}{c}\text { Percentage } \\ \text { NC 92 } \\ \text { nodules }\end{array} & \begin{array}{c}\text { Percentage } \\ \text { TAL 176 } \\ \text { nodules }\end{array} & \begin{array}{c}\text { Total } \\ \text { NC 92 } \\ \text { nodules }\end{array} & \begin{array}{c}\text { Total } \\ \text { TAL 176 } \\ \text { nodules }\end{array} \\ \text { NC 92 } & \text { TAL 176 } & 288 & 21.5 \dagger & 85.4 \dagger & 62 & 246 \\ \text { TAL 176 } & \text { NC 92 } & 332 & 73.5 \dagger & 26.8 \dagger & 244 & 89 \\ \text { S.E. } & & \pm 29.3 & \pm 6.48 & \pm 5.88 & \pm 60.3 & \pm 73.2\end{array}$

- Plants were grown in a medium containing the first inoculant strain $\left(1 \times 10^{4}\right.$ cells $^{-1}$ medium as given in the sequence), and 20 DAS were transplanted to the medium containing the second inoculant strain $\left(1 \times 10^{4}\right.$ cells $\mathrm{g}^{-1}$ medium). The plants were grown for another 40 days harvested and then nodules typed to detect the presence of both strains.

† Total values greater than $100 \%$ are due to double occupancy by two strains. 
Table 3. Performance of Rhizobium strains NC92, TAL 176 and NC 43.3 $\left(10^{8}\right.$ cells seed $\left.{ }^{-1}\right)$ in pot culture, on $\mathrm{cv}$. Robut 33-1

\begin{tabular}{|c|c|c|c|c|c|c|}
\hline $\begin{array}{l}\text { Rhizohiums } \\
\text { strains }\end{array}$ & $\begin{array}{l}\text { Total dry } \\
\text { matter } \\
\text { g plant }\end{array}$ & $\begin{array}{l}\text { Nodule } \\
\text { number } \\
\text { plant }^{-1}\end{array}$ & $\begin{array}{c}\text { Nodule } \\
\text { weight } \\
\text { (mg plant }{ }^{-1} \text { ) }\end{array}$ & $\begin{array}{c}\mathrm{N} \text { in } \\
\text { plant }^{-1} \\
(\%)\end{array}$ & $\begin{array}{l}\text { Total } \mathrm{N}_{2^{-}} \\
\text {fixed } \\
\left(\mathrm{mg} \mathrm{plant}^{-1}\right)\end{array}$ & $\begin{array}{c}\text { Total } \mathrm{N}_{2^{-}} \\
\text {fixed } \\
\text { (mg nodule }\end{array}$ \\
\hline TAL 176 & $4 \cdot 1$ & 173 & 91 & 3.7 & 152 & 0.90 \\
\hline NC $43 \cdot 3$ & $4 \cdot 3$ & 216 & 119 & 4.8 & 205 & 0.96 \\
\hline NC 92 & $4 \cdot 1$ & 169 & 102 & $4 \cdot 0$ & 161 & 0.96 \\
\hline S.E. & $\pm 0 \cdot 20$ & \pm 8.8 & $\pm 6 \cdot 2$ & \pm 0.19 & \pm 10.0 & +0.090 \\
\hline
\end{tabular}

The plants were grown in sterile pot culture inoculated with the treatment strain and supplied with $\mathrm{N}$ free nutrient solution for 42 days.

Table 4. Competitiveness of three strains of Rhizobium (NC 92, NC 43.3 and TAL 176) at different population levels in two-strain combinations in pot culture and as single strains in the field containing $10^{4}$ native Rhizobium $g^{-1} d r y$ soil $\dagger$

\begin{tabular}{|c|c|c|c|c|c|c|}
\hline \multirow[b]{3}{*}{ Inoculum strain } & \multicolumn{6}{|c|}{ Percentage nodules formed by different strains on cv. Robut 33-1 } \\
\hline & \multicolumn{3}{|c|}{ In pot culture, by strain } & \multicolumn{3}{|c|}{ In the field, by strain } \\
\hline & NC 92 & NC $43 \cdot 3$ & TAL 176 & NC 92 & NC $43 \cdot 3$ & TAL 176 \\
\hline \multicolumn{7}{|l|}{$10^{3}+10^{3 *}$} \\
\hline $\mathrm{NC} 92+\mathrm{NC} 43.3$ & $33(35) \ddagger$ & $80(64)_{\ddagger}^{\ddagger}$ & - & $15(23)$ & $17(24)$ & - \\
\hline NC $92+$ TAL 176 & $77(62) \ddagger$ & - & $27(31) t$ & $17(24)$ & - & $0.3(2) \S$ \\
\hline NC $43 \cdot 3+$ TAL 176 & - & $93(75)_{+}^{\ddagger}$ & $1.3(20) \ddagger$ & - & $19(26)$ & $0.5(3) \S$ \\
\hline \multicolumn{7}{|l|}{$10^{6}+10^{6 *}$} \\
\hline $\mathrm{NC} 92+\mathrm{NC} 43 \cdot 3$ & $48(44)_{\ddagger}^{\ddagger}$ & $77(62) \ddagger$ & - & $13(21)$ & $13(21)$ & - \\
\hline NC $92+$ TAL. 176 & $93(75)$ & - & $2(6) \S$ & $14(22)$ & - & $0.5(3) \S$ \\
\hline NC $43 \cdot 3+$ TAL 176 & -- & $97(80)$ & $3(9) \S$ & & $15(23)$ & $1.8(6) \S$ \\
\hline \multicolumn{7}{|l|}{$10^{3}+10^{6 *}$} \\
\hline NC $92+$ TAL 176 & $3(5) \S$ & & $98(84)_{+}^{+}$ & $13(21)$ & - & $0.8(3) \S$ \\
\hline NC $43 \cdot 3+$ TAL 176 & - & $28(30) \ddagger$ & $77(62) \ddagger$ & - & $16(23)$ & $0.8(4) \S$ \\
\hline NC $43 \cdot 3+$ NC 92 & $94(76) \ddagger$ & $8(15)$ & - & $18(25)$ & $14(22)$ & - \\
\hline TAL $176+$ NC 92 & $100(90)$ & -. & $0(0) \S$ & $17(24)$ & - & $0(0) \S$ \\
\hline \multicolumn{7}{|l|}{$\begin{array}{l}\text { Single strains } \\
\text { applied separately }\end{array}$} \\
\hline $10^{3 *}$ & - & & - & $11(19)$ & $13(21)$ & $0.8(3) \S$ \\
\hline $10^{n *}$ & - & - & - & $21(27)$ & $17(24)$ & $1 \cdot 3(5) \S$ \\
\hline S.E. & & $( \pm 2 \cdot 1)$ & & & $( \pm 1 \cdot 6)$ & \\
\hline
\end{tabular}

\section{RESULTS}

All results were tested for significance at the $5 \%$ level of probability and only significant results are discussed here.

Rhizosphere populations tend to reach very similar numbers regardless of the size of the initial inoculum (Table 1). Strain NC 43.3 formed nodules faster than TAL 176 and NC 92 which among themselves did not differ significantly (Fig. 1). The possibility that nodules 


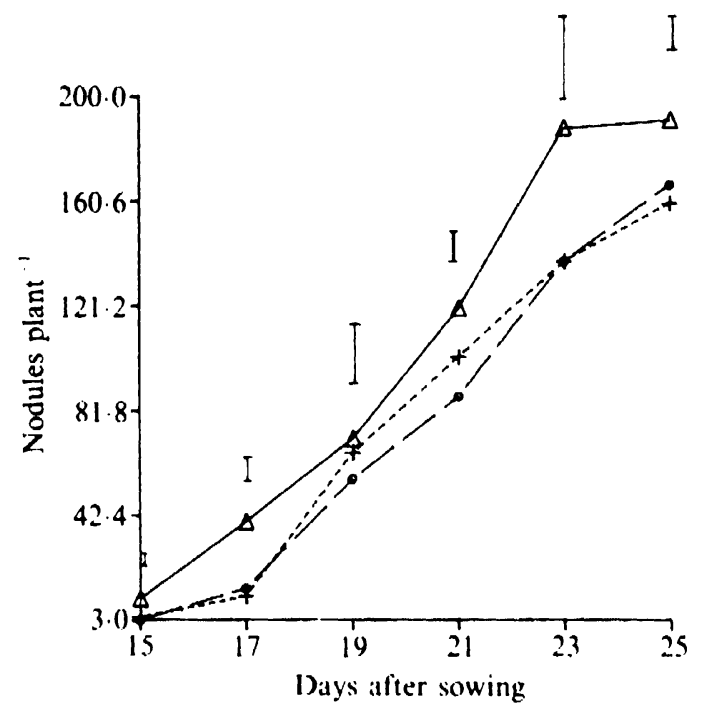

Fig. 1. Number of nodules formed on cv. Robut 331 at different days after sowing in pot culture. $\triangle N^{\prime}$ 43.3: $\odot$ NC 92: + TAL 176. Bars represent \pm s.E.

formed by NC 92 may have an inhibitory effect on nodulation by TAL 176 was investigated by Expt 3. The results indicated that NC 92 nodules did not inhibit subsequent nodulation by TAL 176 or vice versa (Table 2). In fact, strains inoculated after transplantation formed more nodules than the strains inoculated initially.

Nodulation, plant growth and quantities of $\mathrm{N}_{2}$ fixed by TAL 176, NC 43.3, and NC 92 during the growth period are presented in Table 3. Strain NC 43.3 formed more nodules, fixed more $\mathrm{N}_{2}$ and produced plants with a greater $\mathrm{N} \%$ than strains NC 92 and TAL 176 which did not differ from one another. However, the $\mathrm{N}_{2}$ fixed per nodule by NC 43.3 was not significantly more than that fixed by NC 92 or TAL 176.

The competitiveness of these strains, as measured by the percentage of nodules they formed, is given in Table 4. The order of competitive dominance is NC 43.3, NC 92 and TAL 176. TAL 176 formed fewer nodules when mixed in equal proportions with either NC 92 or NC 43.3. However, competitiveness was affected by a number of other competing strains. When $10^{6}$ cells of TAL 176 were mixed with $10^{3}$ cells of NC 43.3 or NC 92, TAL 176 formed $77 \%$ and $98 \%$ nodules respectively in each case. The poor competitiveness of TAL 176 was also observed in the field, even at $10^{6}$ cells seed $^{-1}$, it formed less than $2 \%$ nodules in competition with the native rhizobia (Table 4).

Strain NC 43.3 was found to be a better competitor than NC 92 in two-strain mixtures (Table 4). When individual nodules from two-strain mixtures of NC 43.3 and NC 92 were tested, $31 \%$ were found to contain both NC 92 and NC 43.3 (double occupancy). Strain NC 43.3 was detected in $77 \%$ of the nodules, and NC 92 in only $48 \%$. The total percentage of nodules formed by the two strains in this treatment exceeds $100 \%$ because of double occupancy.

When inoculated as a single strain at $10^{6}$ cells seed $^{-1}$ in a field containing native rhizobia ( $10^{4}$ cells $\mathrm{g}^{-1}$ dry soil), NC 43.3 and NC 92 were found to be equally competitive with the soil rhizobia. Strain NC 43.3 formed only $17.2 \%$ of the total nodules, while NC 92 formed $20 \%$ (Table 4). but this difference was not significant. Total nodules plant ${ }^{-1}$ were not significantly different and data are not presented. 


\section{DISCUSSION}

\section{Rhizosphere colonisation and competition}

The data indicate that strain NC 92 does not possess any advantage of better rhizosphere colonisation than strain TAL 176. However, TAL 176 was a poorer competitor than strain NC 92 or NC 43.3. But, TAL 176 formed most of the nodules when its population outnumbered NC 92 and NC 43.3. At lower cell numbers $\left(10^{3}\right.$ cells seed $\left.^{-1}\right)$ NC 43.3 was a better competitor than NC 92, when either of them were mixed with $10^{6}$ cells seed $^{-1}$ of TAL $^{-1}$ 176. However, the competitiveness of these two strains was not significantly different in field soil containing native rhizobia. Hence competitive ability is dependent on the numbers of interacting rhizobia, and experimental results which have not considered density of competing strains may be misleading.

\section{Differential rates of nodulation and competition}

NC 43.3 was the fastest nodulator. Nodulation rates of NC 92 and TAL 176 were similar, but NC 92 was far more competitive than TAL 176 in both pots and soil. Hence speed of nodulation is not a reliable indicator of competitive ability under all circumstances.

\section{Nitrogen-fixing ability and competitiveness}

The three strains used in these experiments were selected because they ranked high for $\mathrm{N}_{2}-$ fixing ability among the strains in ICRISAT's culture collection (Nambiar, 1985). Of these three strains, NC 43.3 ranked first in $\mathrm{N}_{2}$-fixing ability. However, NC 43.3 formed nodules earlier than NC 92 and TAL 176, which could explain its higher $\mathrm{N}_{2}$-fixation capacity. The results presented above suggest that there is no relationship between $\mathrm{N}_{2}$-fixing ability and competitiveness. TAL 176 was a very poor competitor against a high $\mathrm{N}_{2}$-fixing strain as well as an equally effective strain. The poor competitiveness of TAL 176 cannot be explained by: (a) a slow rate of nodule formation (it formed nodules at the same rate as NC 92); (b) poor survival in the sand-vermiculite medium after inoculation, or (c) an inhibitory effect of nodules formed by other strains on subsequent nodulation by TAL 176. The results provide reasons for the failure of TAL 176 to increase yields in the field (for details see Nambiar, 1985), despite being able to fix $N_{2}$ at the same rate as NC 92 in pot culture. Similarly the relative advantages of NC 43.3 in pot culture can be explained by more rapid formation of nodules by this strain, rather than by the performance of individual nodules. However, the competitive advantages found in NC 43.3 against the other strains in pot culture was not apparent in the field in the presence of native rhizobia. None of the characteristics tested showed any significant advantage of NC 92 over other strains, and it remains to be understood why inoculation with this strain was able to increase yield. These results suggest that the competitiveness of a strain for nodulation is probably governed by both the qualitative and quantitative nature of the metabolites produced by the competing strains, and is not related to the $\mathrm{N}_{2}$-fixing efficiency of the strains.

The authors thank J. H. Williams (ICRISAT), P. S. Nutman (Great Hackworthy Cottage, Exeter, England) and L. R. Frederick (Agency for International Development, Washington D.C., USA) for their critical comments on the manuscript, and A. Vishwanath and $\mathbf{M}$. Subhash Rao for their assistance during the course of these experiments.

\section{REFERENCES}

ANON. (1983a). Annual progress Report 1982-83, Vol. 2, pp. 241-248. Indian Council of Agriculture

Research, Directorate of Oilseeds Research, Rajendranagar, Hyderabad, India. ANON. (1983b). Annual Report 1982. Patancheru, A.P. India: ICRISAT. 200 pp. 
ANON. (1983c). Peanut Research Program, Institute of Agronomic Research. Centre of Maroua, United Republic of Cameroon. Annual Report 1983, pp. 5152.

ANON. (1985). Anmual Report 1984. Patancheru, A.P. India: ICRISAT. $219 \mathrm{pp.}$

CLARK, M. F. \& ADAMS, A. N. (1977). Characteristics of the microplate method of enzyme-linked immunosorbent assay for the detection of plant viruses. Journal of General Virology 34, 475.483.

JOSHI, P. K. \& KULKARNI, J. H. (1983). Response of groundnut to inoculation with single and mixed Rhizobium strains. Indian Journal of Agricultural Science 53, 376-378.

LOPES, E. S. (1977). Ecology of legume-Rhizohium symbiosis. In Limitations and Potentials for Biological Nitrogen Fixation in the Tropics, pp. 173-190. Eds J. Dobereiner, R. H. Burris, and A. Hollaender. Plenum Press, New York.

NAMBIAR, P. T. C. (1985). Response of groundnut (Arachis hypogaea L.) to Rhizobium inoculation in the field: Problems and prospects. MIRCEN Journal of Applied Biology and Biotechnology' 1. 293-309.

NAMBIAR, P. T. C. \& ANJAIAH, V. (1985). Enumeration of rhizobia by enzyme-linked immunosorbent assay. Journal of Applied Bacteriology 58. 187-193.

NAMBIAR, P. T. C. \& DART, P. J. (1980). Studies on nitrogen fixation by groundnut at ICRISAT. In Proceedings of the International Workshop on Groundnuts, pp. 110-124. ICRISAT, Patancheru, A.P. India.

NAmbiaR, P. T. C., DART, P. J., SRINIVASA RAO, B. \& RAVISHANKaR, H. N. (1982). Response of groundnut (Arachis hypogaea) to inoculation. In Biological Nitrogen Fixation technology for Tropical Agriculture, pp. 241-248. Eds P. H. Graham and S. C. Harris. CIAT, Cali, Colombia.

NAMBIAR, P. T. C., RAVISHANKAR, H. N. \& DART, P. J. (1983). Effect of Rhizobium numbers on nodulation and nitrogen fixation in groundnut. Experimental Agriculture 19, 243-250.

NAMBIAR, P. T. C., DART, P. J., SRINIVASA RAO, B. \& RAVISHANKAR, H. N. (1984a). Response of groundnut (Arachis hypogaea L.) to Rhizohium inoculation. Oleagineux 39, 149-155.

NAMbiaR, P. T. C., SRINIVASA RAO, B. \& ANJAIAH, v. (1984h). Studies on competition, persistence and methods of application of a groundnut Rhizohium strain, NC 92. Peanut Science 11, 83-87.

SUBBA RAO, N.S. (1976). Field response of legumes in India to inoculation and fertiliser applications. In Symbiotic Nitrogen Fixation in Plants, pp. 225-268. Fd. P. S. Nutman. Cambridge University Press, London.

VAN DER MERWE. S. P., STRIJDOM, B. W. \& UYS, C. J. (1974). Groundnut response to seed inoculation under extensive agriculture practices in South African soil. Phytophylactica, 6, 295302. 